\title{
Occurrence of perfluorinated compounds in fish from Qinghai-Tibetan Plateau
}

\author{
Yali Shi, Yuanyuan Pan, Ruiqiang Yang, Yawei Wang, Yaqi Cai * \\ State Key Laboratory of Environmental Chemistry and Ecotoxicology, Research Center for Eco-Environmental Science, Chinese Academy of Sciences, P.O. Box 2871, Beijing 100085, \\ People's Republic of China
}

\section{A R T I C L E I N F O}

\section{Article history:}

Received 20 May 2009

Accepted 20 September 2009

Available online 15 October 2009

\section{Keywords:}

PFOS

High mountain fish

Muscle

Qinghai-Tibetan Plateau

\begin{abstract}
A B S T R A C T
Perfluorinated compounds (PFCs) were found in fish muscle collected from high mountain lakes in the Qinghai-Tibetan Plateau, the highest and biggest plateau on Earth. In $96 \%$ of the total fifty-nine fish samples were found detectable perfluorooctane sulfonate (PFOS) as prominent PFCs, while only three for perfluorooctanoate (PFOA). The mean PFOS concentrations in fish muscle ranged $0.21 \mathrm{ng} / \mathrm{g}-5.20 \mathrm{ng} / \mathrm{g}$ based on dry weight, with the maximum in the Palgon Lake $(1.30 \mathrm{ng} / \mathrm{g}-7.54 \mathrm{ng} / \mathrm{g}, \mathrm{dw})$ and the minimum in the Niyang River $(<0.15 \mathrm{ng} / \mathrm{g}-0.32 \mathrm{ng} / \mathrm{g}$, dw) among the seven sampling sites. Long-chain perfluorocarboxylic acids (C10, C11) were also identified in several locations. No significant correlations were observed between PFCs concentrations and sampling altitude or ages (fish). Results of the present work have demonstrated the existence of low level but detectable PFCs pollution in the Qinghai-Tibetan Plateau in China.
\end{abstract}

(c) 2009 Elsevier Ltd. All rights reserved.

\section{Introduction}

Perfluorinated compounds (PFCs) are a new class of emerging organic pollutants. They are highly stable, bio-accumulative and resistant to degradation in the environment. A great number of studies have been available on the contaminations of PFCs in rivers, lakes, and ocean waters (Saito et al., 2004; Sinclair et al., 2006; Ju et al., 2008). The pollution sources were supposed to be the local industrial release as well as citizen activities (Murakami et al., 2008), which may also result in PFCs contamination in the corresponding residents such as fish, mollusks and fish-eating birds (Taniyasu et al., 2003; So et al., 2006). The identification of perfluorooctane sulfonate (PFOS), perfluorooctanoate (PFOA) and other related PFCs in various environmental matrices, including marine mammals (Kannan et al., 2005a) and even humans (Tao et al., 2008), has further confirmed them as widespread contaminants in the environment (Giesy and Kannan, 2001; OECD, Organization for Economic Co-operation and Department, 2002; Tseng et al., 2006). Human and wildlife monitoring researches have demonstrated that they existed not only in the occupational or released exposed area (Olsen et al., 2007; Wilhelm et al., 2008), but also in the general population and natural environment. They have been characterized as tumor promoters (Biegel et al., 2001) and potent peroxisome proliferators (Berthiaume and Wallace, 2002) in toxicity tests, and laboratory animals showed loss of appetite and development was affected when continuously exposed to PFOS or PFOA (Lau et al., 2006).

Much attention has been paid to PFCs and related precursors especially after their identification in remote areas, that are far away

\footnotetext{
* Corresponding author. Tel.: +86106284 9239; fax: +861062849182. E-mail address: caiyaqi@rcees.ac.cn (Y. Cai).
}

from any major industrial activities. The existence of PFCs in the ng/g level in the marine biotas of the Arctic and Antarctic areas has been proved by several reports (Tomy et al., 2004; Martin et al., 2004; Tao et al., 2006), with PFOS as the prominent contaminant. Although the specific sources and transforming mechanism are not yet clear, as perfluorocarboxylates and perfluorooctane sulfonamide (PFOSA) were also found in water and sediment collected from the Arctic (Stock et al., 2007), it is assumed that the transport via ocean currents play an important role in the wide distribution of PFCs. The atmospheric transportation of PFCs precursors can be another important reason. Researches have detected PFCs and some related telomers in urban centers (Kim and Kannan, 2008), as well as in the arctic atmosphere (Stock et al., 2004) and snow (Young et al., 2007), which would provide strong evidence for this hypothesis.

The identification of PFCs has been reported in water (Ju et al., 2008), biota samples (So et al., 2006) and human (Yeung et al., 2006) in China, most of which were carried out mainly in the southeast of China. Therefore, more investigation and systemic data are still necessary for better understanding of the PFCs distribution and pollution in China.

The Qinghai-Tibetan Plateau is located on the eastern Eurasian continent, covering approximately one-fourth of the land area of China. With the average altitude exceeding $4000 \mathrm{~m}$, the Qinghai-Tibetan Plateau is well known as "the roof of the world", and is believed to be far away from modern industrial or commercial activities. However, previous researches performed on POPs in fish, soil and vegetation in the Qinghai-Tibetan Plateau have revealed that the mountain regions have higher concentrations of some persistent organic pollutants (POPs) than expected (Yang et al., 2008). To our knowledge, little information is available concerning distribution of PFCs in this region. Scientists have confirmed that alpine aqueous habitat can accumulate higher concentrations of pollutants because they are 
more vulnerable to pollutants for their low growth rate due to low temperatures and oligotrophic status (Kidd et al., 1995). In order to clarify whether PFCs pollution exists in the Qinghai-Tibetan Plateau, we examined muscles of fish samples collected from 7 high mountain lakes/rivers.

\section{Materials and methods}

\subsection{Chemicals and reagents}

Perfluoroheptanoic acid (PFHpA, >98\%), perflurooctanoic acid (PFOA, 95\%), perfluorononanoic acid (PFNA, 97\%), perluorodecanoic acid (PFDA, 97\%), perfluorododecanoic acid (PFDoDA, 96\%) and perfluorotetradecanoic acid (PFTA, 96\%) were purchased from Alfa Aesar (Lancashire, England), perfluoroundecanoic acid (PFUnDA, 95\%), potassium salts of perfluorohexane sulfonate (PFHxS, $\geq 98 \%$ ) and perfluorooctane sulfonate (PFOS, $\geq 98 \%$ ) were obtained from Sigma-Aldrich (Steinheim, Germany). The internal standard sodium perfluoro- $1-\left(1,2,3,4-{ }^{13} C_{4}\right)$ octanesulfonate $\left({ }^{13} \mathrm{C}_{4}\right.$-PFOS, $\geq 98 \%$ ) was purchased from Wellington Laboratories (Guelph, Ontario, Canada). All stock standards and solutions were prepared in methanol (Fisher Scientific; Pittsburgh, PA, USA) and stored in polypropylene (PP) tubes or vials at $4{ }^{\circ} \mathrm{C}$.

Methanol (HPLC grade) was obtained from Fisher Scientific (Fair Lawn, New Jersey). Ammonium acetate $\left(\mathrm{NH}_{4} \mathrm{OAc}, 97 \%\right)$ and ammonium hydroxide (analytical grade; $\mathrm{v} / \mathrm{v}, 50 \%$ ) were purchased from Alfa Aesar (Ward Hill, Massachusetts). Sodium hydroxide (super grade, $>98 \%$ ) and acetic acid (analytical grade, $\geq 99.5 \%$ ) were obtained from the Beijing Chemical Reagent Factory (China).

\subsection{Sampling}

Fifty-nine fish samples were collected from six mountain lakes, namely Qinghai Lake, Lake Palgon, Manasarovar, Namtso, Yamdro, and Lake Basum in the Qinghai-Tibetan Plateau of China (Fig. 1), as well as Ni-yang River which is just adjacent to Lake Basum. Among the thousands of lakes all over the plateau, most of which are independent with each other, the Namtso, Yamdro and Manasarovar are the three famous holy lakes of Tibet. Namtso is the highest saline lake in the world with an altitude of $4718 \mathrm{~m}$, regarded as one of the remotest and least disturbed aquatic environment; Yamdro is the biggest inner lake beyond the north foot of the Himalayas; Manasarovar is located at an altitude of $4588 \mathrm{~m}, 20 \mathrm{~km}$ southwest of Mt. Kailash, and is one of the highest freshwater lakes in the world. They are regarded to be largely far from production and usage or industrial input of PFCs.

Fishes were collected during the autumn of 2006 and 2007, all the samples were immediately transported to the laboratory after collection, the detailed information of these samples and sampling locations is shown in Table 1. During the collection, measures are adopted to avoid potential contaminations as follows. Each fish sample was individually wrapped in aluminum foil and then put in polyethylene bags. The aluminum foil has been washed with methanol and roasted to dry in advance. All samples were kept in ice-boxes during transportation. On arriving at the laboratory, the skin was removed, only fillets were treated as the sample. Then the muscle tissues were freeze-dried, ground, then wrapped in aluminum foil and stored at $-20^{\circ} \mathrm{C}$ until chemical analysis. All containers used during the process were carefully operated to avoid the introduction of contamination.

\subsection{Sample preparation}

The alkaline digestion method was suggested to be an effective and reliable extraction method for biological samples (Taniyasu et al., 2005). In general, $0.2 \mathrm{~g}$ of tissue sample (dry powder) was extracted with $8 \mathrm{~mL}$ of $10 \mathrm{mM} \mathrm{NaOH}$ (methanol) in a $15 \mathrm{~mL}$ PP tube for $16 \mathrm{~h}$, $10 \mathrm{ng}$ of ${ }^{13} \mathrm{C}_{4}$-PFOS was added as the internal standard prior to

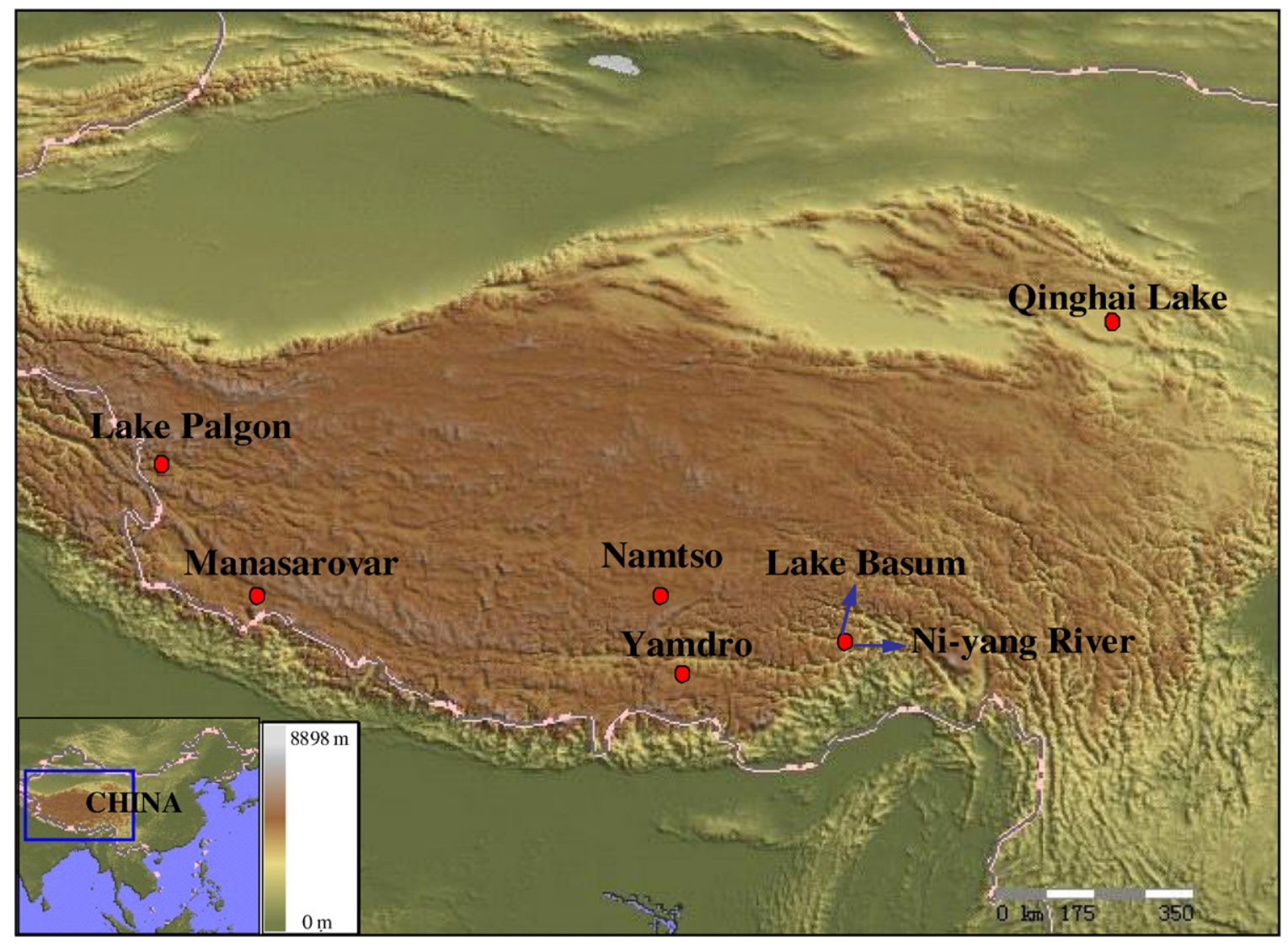

Fig. 1. Sampling locations in the Qinghai-Tibetan Plateau of China. 
Table 1

Details of fish samples collected from the Qinghai-Tibetan Plateau.

\begin{tabular}{|c|c|c|c|c|c|c|c|}
\hline Sites & Latitude $(\mathrm{N})$ & Longitude (E) & Altitude (m) & No. of samples & Species & Age (year) & Lipid (\%) \\
\hline Qinghai Lake & $36^{\circ} 43.022^{\prime}$ & $100^{\circ} 15.101^{\prime}$ & 3225 & 7 & Gymnocypris przewalskii & na $^{a}$ & 2.70 \\
\hline Lake Palgon & $33^{\circ} 31.191^{\prime}$ & $79^{\circ} 52.881^{\prime}$ & 4242 & 8 & Racoma tibetanus & $9.9(7-13)$ & 2.64 \\
\hline Manasarovar & $30^{\circ} 43.017^{\prime}$ & $81^{\circ} 27.670^{\prime}$ & 4588 & 7 & na & $6.3(5-7)$ & 1.58 \\
\hline Namtso & $30^{\circ} 53.643^{\prime}$ & $90^{\circ} 52.095^{\prime}$ & 4718 & 10 & Gymoncypris namensis & $10.4(7-16)$ & 1.73 \\
\hline Yamdro & $29^{\circ} 85.475^{\prime}$ & $90^{\circ} 28.351^{\prime}$ & 4441 & 14 & Gymoncypris waddellii & $9.1(5-13)$ & 1.62 \\
\hline \multirow[t]{2}{*}{ Lake Basum } & $30^{\circ} 00.210^{\prime}$ & $93^{\circ} 54.376^{\prime}$ & 3538 & 3 & Racoma biddulphi Gunther & $7(6-8)$ & 3.06 \\
\hline & & & & 2 & na & na & 7.50 \\
\hline \multirow[t]{2}{*}{ Ni-yang River } & na & na & na & 4 & Racoma biddulphi Gunther & $5.2(4-6)$ & 1.94 \\
\hline & & & & 4 & Schizopygopsis malacanthus Herzenstein & $5(4-6)$ & 2.75 \\
\hline
\end{tabular}

${ }^{\text {a }}$ No information was available.

extraction. After digestion and centrifugation, $4 \mathrm{~mL}$ of the supernatant was diluted in $36 \mathrm{~mL}$ water in a PP tube, which was used for SPE using an Oasis ${ }^{\circledR}$ WAX cartridge ( 6 cc, 150 mg; Waters Corp. Milford, USA). The target analytes were eluted with $4 \mathrm{~mL}$ of methanol and $4 \mathrm{~mL}$ of $0.1 \%$ ammonium hydroxide (methanol) at a flow rate of $1 \mathrm{drop} / \mathrm{s}$. The $8 \mathrm{~mL}$ of eluate was concentrated to $1 \mathrm{~mL}$ under nitrogen for injection. Each cartridge was used only once.

\subsection{Chemical analysis}

The identification of nine PFCs in samples was accomplished with a high performance liquid chromatograph equipped with an electrospray ionization tandem mass spectrometer (HPLC-ESI/MS/MS) operated in negative mode. The separation was achieved on a Dionex Acclaim 120 C18 column (4.6 mm i.d. $\times 150 \mathrm{~mm}$ length, $5 \mu \mathrm{m}$; Dionex, Sunnyvale, CA, USA) with an aliquot of $10 \mu \mathrm{L}$ injection. A $10 \mathrm{~min}$ dualistic gradient at a flow rate of $1.0 \mathrm{~mL} / \mathrm{min}$ was adopted which began with $28 \% 50 \mathrm{mM} \mathrm{NH}_{4} \mathrm{OAc}$, and $\mathrm{NH}_{4} \mathrm{OAc}$ was reduced to $5 \%$ at $4 \mathrm{~min}$ before returning to the original condition at $7 \mathrm{~min}$. Then the quantitative analyses were conducted using ESI/MS/MS (API 3200; Applied Biosystems/MDS SCIEX, US).

\subsection{Quality assurance/quality control (QA/QC)}

Polytetrafluorethylene (PTFE) materials had been removed from the equipment or replaced by stain-steel or PEEK vessels. Polypropylene (PP) or glass tubes and containers were rinsed with methanol and water before use.

PFCs standard (1 ng) was treated following the same procedure as the samples and PFCs were well recovered with recoveries 97.6\%$145 \%$ (Table 2). The results indicated that the SPE extraction is sufficient to support quantitative extraction. Duplicate matrix spikes were prepared for tissue samples. The fish samples $(0.2 \mathrm{~g}, n=9)$ were spiked with $2 \mathrm{ng}$ of target standards, aged for $0.5 \mathrm{~h}$, and passed through the whole procedure. The recoveries were in range of $74.3 \%$ -

Table 2

Recoveries for individual PFCs with alkaline digestion and SPE.

\begin{tabular}{lllll}
\hline Analytes & & $\begin{array}{l}\text { SPE recoveries }^{\mathrm{a}} \\
(\%)\end{array}$ & $\begin{array}{l}\text { Spiked recoveries } \\
(\%)\end{array}$ & $\begin{array}{l}\text { RSD, } n=9 \\
(\%)\end{array}$ \\
\hline PFHxS & $398.7 / 79.9$ & 103.4 & $111.1(103.8-120)$ & 5.7 \\
PFHpA & $362.9 / 318.9$ & 120.8 & $106.9(95.9-111.7)$ & $5.9(n=5)$ \\
PFOA & $412.8 / 369$ & 116.8 & $108.4(88.1-119.7)$ & 9.6 \\
PFOS & $498.8 / 79.9$ & 103.8 & $102.7(96.5-112.0)$ & 4.9 \\
PFNA & $462.9 / 418.9$ & 102.0 & $122.9(114.8-127.4)$ & 5.7 \\
PFDA & $512.7 / 468.9$ & 105.8 & $100.3(93.9-107.1)$ & 6.0 \\
PFUnDA & $562.8 / 519$ & 99.2 & $96.6(91.8-103.4)$ & 3.8 \\
PFDoDA & $612.9 / 569$ & 97.6 & $74.3(61.6-80.8)$ & 9.1 \\
PFTA & $712.9 / 669$ & 144.6 & $77.0(61.6-90.4)$ & 10.6 \\
\hline
\end{tabular}

a Standard mixture was diluted with water and got through the same extraction procedure as real samples.
$123 \%$, and a satisfying reproduction was obtained, shown in Table 2. However, concentrations of PFCs in the samples were not corrected for the recovery percentages.

The linearity was evaluated by eight points of different concentrations covering a range of $50 \mathrm{ng} / \mathrm{L}-20,000 \mathrm{ng} / \mathrm{L}$. Each concentration was spiked with $5 \mathrm{ng}$ of ${ }^{13} \mathrm{C}_{4}$-PFOS as the internal standard. Analysis and quantification were performed on the basis of Analyst 1.4.1 software (API 3200; Applied Biosystems/MDS SCIEX, US). Curves were prepared using a quadratic " $1 / \mathrm{x}^{2}$ " weighted regression and the calibrations showed strong linearity with correlation coefficients $>0.99$. The limits of detection (LODs) were determined on the basis of a signal-to-noise ratio of $3(\mathrm{~S} / \mathrm{N}=3)$ or greater, which were $0.15 \mathrm{ng} / \mathrm{g}$ for PFHxS and PFOS, $0.5 \mathrm{ng} / \mathrm{g}$ for PFHpA, PFOA and PFNA, $0.7 \mathrm{ng} / \mathrm{g}$ for PFUnDA and PFDoDA, and $1.0 \mathrm{ng} / \mathrm{g}$ for PFDA and PFTA, respectively. The smallest concentrations of the standard calibration were repeatedly injected and the peak areas showed fine reproducibility with the relative standard deviation (RSD) below $11 \%(n=7)$. The eight-point standard calibration was conducted before and after each analysis. $1 \mu \mathrm{g} / \mathrm{L}$ PFCs was injected during the analysis for calibration verification and to ensure the sensitivity stability.

\subsection{Statistical analysis}

The SPSS 13.0 software was used for statistical analysis. Concentrations below LOD were assigned as $\mathrm{LOD} / \sqrt{ } 2$ during the calculations. A Pearson correlation analysis was used to examine possible correlations among various PFCs in samples, and that between PFCs concentrations with other parameters such as fish age, weight and lipid\%. The Kolmogorov-Smirnov test (one-sample K-S test) was conducted to test the normality of the data set. Correlation between PFOS concentrations and sampling altitude was based on the Spearman correlation test. The Kruskal Wallis test was used to show if there was a significant difference between PFOS concentrations with fish species.

\section{Results and discussion}

PFHxS, PFDoDA and PFTA were detected in none of the 59 samples. Since trace concentration levels of PFHpA and PFNA were observed in procedure blank, which was $0.10 \mu \mathrm{g} / \mathrm{L}$ and $0.07 \mu \mathrm{g} / \mathrm{L}$, respectively, the concentrations of PFCs were given and discussed only for PFOA, PFOS, PFDA and PFUnDA.

PFOS was the most prominent PFCs found in the muscles of fish collected from the Qinghai-Tibetan Plateau (Table 3), which was consistent with results of fishes analyzed in the Canadian Arctic (Stock et al., 2007). Tseng et al. (2006) and Berger et al. (2009) also reported that in edible fish muscle PFOS concentration level was higher than that of PFOA. PFOA was also found in fish samples, as well as PFCs with longer carbon chain (PFDA and PFUnDA) (Table 1), but only in very few samples. PFOS was detected in $96 \%$ of fish samples (59), whereas PFOA was found above the LOD in only 3 of the 59 samples investigated. Large variations existed among sampling locations and individuals (Table 3). The highest concentrations of PFOS $(7.54 \mathrm{ng} / \mathrm{g}, \mathrm{dw}$ ) was found in Racoma tibetanus from Lake Palgon. Mean concentrations of PFOS were ranged $0.21 \mathrm{ng} / \mathrm{g}-5.2 \mathrm{ng} / \mathrm{g}$ (dw), while the lowest one was in the Ni-yang River (Schizopygopsis malacanthus Herzenstein) (Table 3). Generally, the present results were the lowest ever reported as far as the available data we got. PFOS concentrations in fish measured in the Qinghai-Tibetan Plateau were lower than that reported in fish from Guangzhou, Zhoushan 
Table 3

PFCs in fish muscle samples from the Qinghai-Tibetan Plateau (ng/g, dry weight).

\begin{tabular}{|c|c|c|c|c|c|}
\hline Sites & Species & PFOA & PFOS & PFDA & PFUnDA \\
\hline Qinghai Lake & Gymnocypris przewalskii & $<0.5$ & $1.71(1.26-1.98)$ & $1.22(<1.0-1.95)$ & $1.85(1.02-2.75)$ \\
\hline Lake Palgon & Racoma tibetanus & $(<0.5-1.86)(2 / 8)^{\mathrm{a}}$ & $5.20(1.30-7.54)$ & $1.12(<1.0-1.52)$ & $0.90(<0.7-1.42)$ \\
\hline Manasarovar & na & $<0.5$ & $1.09(0.32-1.68)$ & $<1.0$ & $<0.7$ \\
\hline Namtso & Gymoncypris namensis & $<0.5$ & $0.831(<0.15-1.28)$ & $<1.0$ & $<0.7$ \\
\hline Yamdro & Gymoncypris waddellii & $<0.5$ & $2.27(1.09-4.93)$ & $<1.0$ & $(<0.7-0.75)$ \\
\hline \multirow[t]{2}{*}{ Lake Basum } & Racoma biddulphi Gunther & $<0.5$ & $0.76(0.60-0.88)$ & $<1.0$ & $<0.7$ \\
\hline & na & $<0.5$ & $1.17(0.70-1.65)$ & $<1.0$ & $1.02(0.93-1.12)$ \\
\hline \multirow[t]{2}{*}{ Ni-yang River } & Racoma biddulphi Gunther & $<0.5$ & $1.34(1.07-1.59)$ & $<1.0$ & $<0.7$ \\
\hline & Schizopygopsis malacanthus Herzenstein & $(1.38)(1 / 4)$ & $0.21(<0.15-0.32)$ & $<1.0$ & $<0.7$ \\
\hline
\end{tabular}

a The mean concentrations were not evaluated for low detect ratio, only individual concentrations were presented.

(Gulkowska et al., 2006) and Taiwan (Tseng et al., 2006), and were also less than those from Eastern Arctic (Tomy et al., 2004), Canadian Arctic (Martin et al., 2004; Stock et al., 2007) and the Great Lakes (Kannan et al., 2005b).

The mean concentration of PFOS in fish samples from Lake Palgon was $5.20 \mathrm{ng} / \mathrm{g}$ (dw) (see Table 3), which was several times higher than that from other locations $(0.21 \mathrm{ng} / \mathrm{g}$ $1.71 \mathrm{ng} / \mathrm{g}, \mathrm{dw})$. The second and third places were in the Yamdro $(2.27 \mathrm{ng} / \mathrm{g}, \mathrm{dw})$ and the Qinghai Lake (1.71 ng/g, dw), followed by Manasarovar (1.09 ng/g, dw). Interestingly, the Yamdro and the Manasarovar, as well as Lake Palgon were all in and near the border line, adjacent to Bhutan, Nepal and India. PFOS was found extremely low in the Ni-yang River (Schizopygopsis malacanthus Herzenstein) with concentrations mostly near the LOD (mean $0.21 \mathrm{ng} / \mathrm{g} ;<0.15 \mathrm{ng} / \mathrm{g}-0.32 \mathrm{ng} / \mathrm{g}$, dw) (see Table 3). The mean concentration of PFOS in Racoma biddulphi Gunther in the same site was $1.34 \mathrm{ng} / \mathrm{g}(1.07 \mathrm{ng} / \mathrm{g}-1.59 \mathrm{ng} / \mathrm{g}$, dw), approximately twice as that in Lake Basum nearby. When we only consider the spatial difference, PFOS level was about $0.90 \mathrm{ng} / \mathrm{g}$ in both sampling sites, which was a little higher than that in the Namtso (mean $0.831 \mathrm{ng} / \mathrm{g},<0.15 \mathrm{ng} / \mathrm{g}-1.28 \mathrm{ng} / \mathrm{g}$, dw) (Table 3). Since these three sampling sites are relatively far away from the border line of China, the results of present work will be a favorable proof to the possibility that the PFOS distribution was affected by the monsoon. Previous study had observed relatively higher levels of POPs in the plateau region, and suggested the atmospheric deposition to be the source of POPs (Zhang et al., 2003), through which POPs were brought by air masses from the Indian subcontinent and the Eurasian continent (Li et al., 2006). Therefore PFCs in the QinghaiTibetan Plateau region may be also influenced by a similar mechanism. However, further researches are needed to get more valuable proofs for the hypothesis. In addition, the Kruskal Wallis test showed that there was a statistically significant difference between PFOS concentrations with fish species, thus the different PFOS concentrations in the plateau were perhaps to some extent due to the different fish species, although the fishes were from each individual site. Studies had also shown that the diet choices, exposure and differences in metabolic capabilities would influence the concentration of organic pollutants (Tomy et al., 2004).

It is hypothesized that the orographic cold-trapping effect for some POPs may be particularly pronounced in the Qinghai-Tibetan Plateau due to dramatic altitudinal gradients (Li and Macdonald, 2005), however, significant negative correlations between PFOS concentrations and sampling altitude were found in the further analysis based on the Spearman rank correlation (2-tailed) analysis $(\alpha<0.01)$. We have also evaluated the relationship between PFOS concentrations with the fish age, weight and lipid\% for each species of fish, but no significant correlation was observed.

Detectable PFDA and PFUnDA also occurred in four sampling locations, and PFUnDA was more often detected than PFDA (Table 3), and the occurrence of long-chain PFCs has been reported in fish of the Arctic (Martin et al., 2004). The $\sum$ PFCs detected in fish muscle samples ranged from $0.76 \mathrm{ng} / \mathrm{g}$ to $9.69 \mathrm{ng} / \mathrm{g}$ (dw) in the Qinghai-Tibetan Plateau.

It is widely accepted that PFOS and related PFCs accumulate preferentially in the blood or liver rather than in lipids (Martin et al., 2003). However, in the present study, PFUnDA were found to be significantly correlated with the lipid\% of fish samples in Lake Palgon $(p<0.05)$. Significant correlations were found between PFOS with PFDA and PFUnDA in Lake Palgon $(p<0.01)$. In Qinghai Lake, PFDA was also observed to be significantly correlated with PFUnDA $(p<0.01)$. These results suggest that there may be co-exposures to these compounds in the environment or their corresponding precursors.

The major difference between the Qinghai-Tibetan Plateau and other places studied in China, such as Dalian (Ju et al., 2008) and south of China (So et al., 2007), was that no predicted sources can be directly related to the production and usage of PFCs products in this region. Most of the mountain lakes in the plateau are located in high altitude, and the water is mainly generated from the snow and ice of the high mountains around them. Since few major industrial/modern activities have been found at/near the sampling locations, the most likely source of the PFCs is the atmosphere. Moreover, studies have confirmed the long-range atmospheric transport of perfluorinated homologous compounds in previous works in the Arctic region (Stock et al., 2004; Young et al., 2007).

\section{Conclusions}

In the present work, the occurrence of PFCs was found in almost all samples analyzed and PFOS was the prominent PFC, although in very low levels. For the difficulty of sampling, samples and data were limited which had made it difficult to get intensive understanding of the geographical distribution and precise influencing factors of PFCs in the Qinghai-Tibetan Plateau. However, the observation of PFOS and other related PFCs in this region has provided a conceivable proof for the existence of PFCs pollution in the Qinghai-Tibetan Plateau. The potential contamination source of aquatic environment may be related to atmospheric deposition in this area. Then the Qinghai-Tibetan Plateau may be an important indicator region to study the long-range atmospheric transport and fate of PFCs. Further research is still necessary to get better understanding of the PFCs distribution and transforming mechanisms in the Qinghai-Tibetan Plateau.

\section{Acknowledgments}

This work was jointly supported by the High-Technology Research and Development Program of China (863 Project No. 2007AA06Z405), the National Natural Science Foundation of China (No. 40601101; 40873078) and by the Major Research Program of the Chinese Academy of Sciences (No. KZCX2-YW-420-1).

\section{References}

Berger U, Glynn A, Holmstrom KE, Berglund M, Ankarberg EH, Tornkvist A. Fish consumption as a source of human exposure to perfluorinated alkyl substances in Sweden-analysis of edible fish from Lake Vattern and the Baltic Sea. Chemosphere 2009;76:799-804.

Berthiaume J, Wallace KB. Perfluorooctanoate, perfluorooctanesulfonate, and N-ethyl perfluorooctanesulfonamido ethanol; peroxisome proliferation and mitochondrial biogenesis. Toxicol Lett 2002;129:23-32.

Biegel LB, Hurtt ME, Frame SR, O'Connor J, Cook JC. Mechanisms of extrahepatic tumor induction by peroxisome proliferators in male CD rats. Toxicol Sci 2001;60:44-55.

Giesy JP, Kannan K. Global distribution of perfluorooctane sulfonate in wildlife. Environ Sci Technol 2001;35:1339-42.

Gulkowska A, Jiang Q, So MK, Taniyasu S, Lam PKS, Yamashita N. Persistent perfluorinated acids in seafood collected from two cities of China. Environ Sci Technol 2006;40:3736-41.

Ju XD, Jin YH, Sasaki K, Saito N. Perfluorinated surfactrant in surface, subsurface, microlayer from Dalian coastal waters in China. Environ Sci Technol 2008;42:3538-42.

Kannan K, Yun SH, Evans TJ. Chlorinated, brominated, and perfluorinated contaminants in livers of polar bears from Alaska. Environ Sci Technol 2005a;39:9057-63.

Kannan K, Tao L, Sinclair E, Pastva SD, Jude DJ, Giesy JP. Perfluorinated compounds in aquatic organisms at various trophic levels in a Great Lakes food chain. Arch Environ Contam Toxicol 2005b;48:559-66.

Kidd KA, Schindler DW, Muir DCG, Lockhart WL, Hesslein H. High concentrations of toxaphene in fishes from a subarctic lake. Science 1995;269:240-2.

Kim S-K, Kannan K. Perfluorinated acids in air, rain, snow, surface runoff, and lakes: relative importance of pathways to contamination of urban lakes. Environ Sci Technol 2008;41:8328-34.

Lau C, Thibodeaux JR, Hanson RG, Narotsky MG, Rogers JM, Lindstrom AB, et al. Effects of perfluorooctanoic acid exposure during pregnancy in the mouse. Toxicol Sci 2006;90:510-8.

Li YF, Macdonald RW. Sources and pathways of selected organochlorine pesticides to the Arctic and the effect of pathway divergence on $\mathrm{HCH}$ trends in biota: a review. Sci Total Environ 2005;342:87-106.

Li J, Zhu T, Wang F, Qiu XH, Lin WL. Observation of organochlorine pesticides in the air of the Everest region. Ecotoxicol Environ Saf 2006;63:33-41.

Martin JW, Mabury SA, Solomon KR, Muir DCG. Bioconcentration and tissue distribution of perfluorinated acids in rainbow trout (Oncorhynchus mykiss). Environ Toxicol Chem 2003;22:196-204. 
Martin JW, Smithwick MM, Braune MB, Hoekstra PF, Muir DCG, Mabury SA Identification of long-chain perfluorinated acids in biota from the Canadian Arctic. Environ Sci Technol 2004;38:373-80.

Murakami M, Imamura E, Shinohara H, Kiri K, Muramatsu Y, Harada A, et al. Occurrence and sources of perfluorinated surfactants in rivers in Japan. Environ Sci Technol 2008;42:6566-72

OECD (Organization for Economic Co-operation and Department). Co-operation on existing chemicals: hazard assessment of perfluorooctane sulfonate (PFOS) and its salts; 2002. ENV/JM/RD (2002) 17/FINAL.

Olsen GW, Burris JM, Ehresman DJ, Froehlich JW, Seacat AM, Butenhoff JL, et al. Half-life of serum elimination of perfluorooctanesulfonate, perfluorohexanesulfonate, and perfluorooctanoate in retired fluorochemical production workers. Environ Health Perspect 2007;115:1298-305.

Saito N, Harada K, Inoue K, Sasaki K, Yoshinaga T, Koizumi A. Perfluorooctanoate and perfluorooctane sulfonate concentrations in surface water in Japan. J Occup Health 2004;46:49-59.

Sinclair E, Mayack DT, Roblee K, Yamashita N, Kannan K. Occurrence of perfluoroalkyl surfactants in water, fish, and birds from New York State. Arch Environ Contam Toxicol 2006;50:398-410.

Stock NL, Lau FK, Ellis DA, Martin JW, Muir DCG, Mabury SA. Polyfluorinated telomer alcohols and sulfonamides in the North American troposphere. Environ Sci Technol 2004:38:991-6.

Stock NL, Furdui VI, Muir DCG, Mabury SA. Perfluoroalkyl contaminants in the Canadian Arctic: evidence of atmospheric transport and local contamination. Environ Sci Technol 2007;41:3529-36.

So MK, Taniyasu S, Lam PKS, Zheng GJ, Giesy JP, Yamashita N. Alkaline digestion and solid phase extraction method for perfluorinated compounds in mussels and oysters from South China and Japan. Arch Environ Contam Toxicol 2006;50:240-8.

So MK, Miyake Y, Yeung LW, Ho YM, Taniyasu S, Postkowski P, et al. Perfluorinated compounds in the Pearl River and Yangtze River of China. Chemosphere 2007;68: 2085-95.
Taniyasu S, Kannan K, Horii Y, Hanari N, Yamashita N. A survey of perfluorooctane sulfonate and related perfluorinated organic compounds in water, fish, birds, and humans from Japan. Environ Sci Technol 2003;37:2634-9.

Taniyasu S, Kannan K, So MK, Gulkowska A, Sinclair E, Okazawa T, et al. Analysis of fluorotelomer alcohols, fluorotelomer acids, and short- and long-chain perfluorinated acids in water and biota. J Chromatogr A 2005;1093:89-97.

Tao L, Kannan K, Kajiwara N, Costa M, Fillmann G, Takahashi S, et al. Perfluorooctanesulfonate and related fluorochemicals in albatrosses, elephant seals, penguins, polar skuas from the Southern Ocean. Environ Sci Technol 2006;40:7642-8.

Tao L, Kannan K, Wong CM, Arcaro KF, Butenhoff JL. Perfluorinated compounds in human milk from Massachusetts, U.S.A. Environ Sci Technol 2008;42:3096-101.

Tomy GT, Budakowski W, Halldorson T, Helm PA, Stern GA, Friesen K, et al. Fluorinated organic compounds in an Eastern Arctic marine food web. Environ Sci Technol 2004;38:6475-81.

Tseng CL, Liu LL, Chen CM, Ding WH. Analysis of perfluorooctanesulfonate and related fluorochemicals in water and biological tissue samples by liquid chromatographyion trap mass spectrometry. J Chromatogr A 2006;1105:119-26.

Wilhelm M, Kraft M, Rauchfuss K, Hölzer J. Assessment and management of the first German case of a contamination with perfluorinated compounds (PFC) in the region Sauerland, North Rhine-Westphalia. J Toxicol Environ Health 2008;71:725-33.

Yang RQ Yao TD, Xu BQ Jiang GB, Zheng XY. Distribution of organochlorine pesticides (OCPs) in conifer needles in the southeast Tibetan Plateau. Environ Pollut 2008:153:90-100.

Yeung LW, So MK, Jiang GB, Taniyasu S, Yamashita N, Song MY, et al. Perfluorooctanesulfonate and related fluorochemicals in human blood samples from China. Environ Sci Technol 2006;40:715-20.

Young CJ, Furdui VI, Franklin J, Koerner RM, Muir DCG, Mabury SA. Perfluorinated acids in Arctic snow: new evidence for atmospheric formation. Environ Sci Technol 2007; $41: 3455-61$.

Zhang WL, Zhang G, Qi SH, Peng PA. A preliminary study of organochlorine pesticides in water and sediments from two Tibetan lakes. Geochimica 2003;32:363-7. 